Volume 11

Issue 3 Global Approaches to Atrocity

Prevention: Theory, Practice, and the State of

the Field

\title{
3-2018
}

\section{Improving Intervention Decisions to Prevent Genocide: Less \\ Muddle, More Structure}

Robin Gregory

Decision Research \& University of British Columbia

Michael Harstone

Compass Resource Management Ltd.

Paul Slovic

Decision Research \& University of Oregon

Follow this and additional works at: https://digitalcommons.usf.edu/gsp

\section{Recommended Citation}

Gregory, Robin; Harstone, Michael; and Slovic, Paul (2018) "Improving Intervention Decisions to Prevent Genocide: Less Muddle, More Structure," Genocide Studies and Prevention: An International Journal: Vol.

11: Iss. 3: 109-127.

DOI:

http://doi.org/10.5038/1911-9933.11.3.1496

Available at: https://digitalcommons.usf.edu/gsp/vol11/iss3/12

This Articles is brought to you for free and open access by the Open Access Journals at Digital Commons @ University of South Florida. It has been accepted for inclusion in Genocide Studies and Prevention: An International Journal by an authorized editor of Digital Commons @ University of South Florida. For more information, please contact digitalcommons@usf.edu. 


\section{Improving Intervention Decisions to Prevent Genocide: Less Muddle, More Structure}

\section{Acknowledgements}

This material is based upon work supported by the National Science Foundation under Grant No. 1440074. Any opinions, findings, and conclusions or recommendations expressed in this material are those of the authors and do not necessarily reflect the views of the National Science Foundation. 
Improving Intervention Decisions to Prevent Genocide: Less Muddle, More Structure

\author{
Robin Gregory \\ Decision Research \& University of British Columbia \\ Vancouver, BC, Canada \\ Michael Harstone \\ Compass Resource Management Ltd. \\ Vancouver, BC, Canada \\ Paul Slovic \\ Decision Research \& University of Oregon \\ Eugene, OR, USA
}

\title{
Introduction
}

Concerns about people fleeing war-torn homelands have become part of our daily news. Vivid images of destroyed cities, brutally murdered civilians, and crowded refugee camps have resulted in an outpouring of compassion and humanitarian aid. Many countries, including the United States, are being pressed to simultaneously undertake actions to halt genocide ${ }^{1}$ and to open their doors to new waves of refugees. As a result, policy makers and citizens are asking themselves: How do we decide when to get involved and if we are doing enough to halt the killing (or its threat)? What types of actions might be most effective? How can we ensure that things go right? And what constitutes a successful or unsuccessful intervention?

The importance of preventing genocide is not at issue. The doctrine of responsibility to protect $(\mathrm{R} 2 \mathrm{P}),{ }^{2}$ articulated in 2005, permits the international community to intervene in the affairs of a sovereign state if it fails to protect its population from mass atrocity crimes. In the United States, the Executive Summary of the Genocide Prevention Task Force, co-chaired by Madeleine Albright and William Cohen, begins by emphasizing "the fundamental reality that genocide and mass atrocities threaten American values and interests." ${ }^{\prime 3}$ President Obama supported and strengthened this position by proclaiming, as part of Presidential Directive 10, the establishment of the Atrocities Prevention Board (APB) and by stating that "Preventing mass atrocities and genocide is a core national security interest and a core moral responsibility of the United States." ${ }^{4}$

It might then be assumed that clear criteria and policies are in place for deciding when and what to do. The reality, in sharp contrast, is that the absence of coherent procedures for addressing intervention decisions is widely acknowledged. For example, in their comprehensive 2008 review of genocide prevention strategies, Albright and Cohen wrote that "Simply put, the U.S. government does not have an established, coherent policy for preventing and responding to genocide and mass atrocities. ${ }^{5}$ Drawing on techniques from decision analysis, psychology, and negotiation analysis, we highlight a general approach to assessing genocide prevention decisions that we believe could provide decision makers with insights about how to construct defensible intervention policies and link proposed actions to national values in a manner that promotes consistency, efficiency, and defensibility.

\footnotetext{
${ }^{1}$ This paper follows the lead of U.S. Executive Order No. 13729 and is concerned with decisions to prevent or reduce "large-scale and deliberate attacks on civilians," a concept that includes actions which could be described as genocide or as mass atrocities. Barack Obama, Executive Order 13729 of May 18, 2016, A Comprehensive Approach to Atrocity Prevention and Response (Washington, DC: The White House, 2016).

${ }^{2}$ United Nations, General Assembly Resolution 60/1, 2005 World Summit Outcome, October 24, 2005 (UN Doc. A/RES/60/1), paras. 138-140.

${ }^{3}$ Madeleine K. Albright and William S. Cohen, Preventing Genocide: A Blueprint for U.S. Policymakers (Washington, DC: United States Holocaust Memorial Museum, 2008), xv.

${ }^{4}$ Barack Obama, Presidential Directive Study 10, August 4, 2011. (Washington, DC: Office of the Federal Register, 2011).

${ }^{5}$ Albright and Cohen, Preventing Genocide, 3.
} 
Although we lack direct experience as senior-level policy officials, our research-as academics and frequent advisors to governments - has focused on understanding how people both do and should make decisions characterized by multiple dimensions of value, uncertain consequences, and difficult tradeoffs. This characterization applies to most decisions concerning genocide prevention but also to a host of other tough public policy choices facing governments such as responses to climate change, storage of high-level nuclear wastes, or prevention of terrorism. Each of these national-level policy choices is said to have an influence on "national security" and the long-term "national interest" - two terms that often surface as part of discussions of genocide prevention. In each of these diverse policy arenas the consequences of decisions typically are subject to uncertainty (and thus good outcomes are not guaranteed). Nevertheless, appropriate decision-making approaches have the capability to improve the quality of outcomes by identifying choices that better align with and achieve the considered interests of decision makers. As President Obama stated when discussing U.S. policies in the Middle East, "We have to be able to distinguish between these problems analytically, so that we're not using pliers where we need a hammer, and we're not using a battalion when what we should be doing is partnering with the local government." 6

\section{Evaluating Tough Intervention Choices}

Everyone would acknowledge the many difficulties facing national leaders making decisions about intervening in a foreign country in hopes of preventing genocide and mass atrocities. Whether the U.S. (or any nation) should intervene and attempt to stop genocide is complicated, on many levels. ${ }^{7}$ Such choices place a cognitive demand on decision makers because they involve multiple dimensions of value and a wide range of possible alternative actions. The decision context typically is characterized by numerous constraints including insufficient time, limited information, and scarce financial resources. Intervention decisions also involve strong emotions because people's livesforeign as well as domestic - are at issue and because decision makers feel a moral responsibility for the outcomes of their choices.

In a widely cited speech to a group of foreign policy experts meeting at the Holocaust Memorial Museum in Washington, DC, ${ }_{1}^{8}$ then Secretary of State Clinton emphasized the importance of preventing mass atrocities when she said "The United States and our partners must act before the wood is stacked or the match is struck." She also noted that intervention efforts should "ensure that all our tools and resources are being put to good use." However, there was no explicit linkage to methods or deliberative processes that might provide a practical and generalizable template for assessing what it means to put resources to "good use" - presumably, a reference to undertaking genocide prevention efforts that help to achieve (remembering Albright and Cohen) the Nation's "values and interests."

Two basic approaches typically are used to come up with strategies and action plans in the face of difficult choices. The first is to rely on past experiences and informed intuition. For such decisions, some maintain, there is no substitute for experience and little role for external decision aids or methods. This perspective - "decision making as an art" - is a reasonable characterization of much of medicine, ${ }^{9}$ law, ${ }^{10}$ and the military: ${ }^{11}$ good decisions will arise naturally from discussions among a small group of experienced experts. The alternative perspective-"decision making as a

\footnotetext{
${ }^{6}$ David Remnick, “Going the Distance," The New Yorker, January 24, 2014, accessed May 11, 2017, http://www.newyorker. com/magazine/2014/01/27/going-the-distance-david-remnick.

${ }^{7}$ Samantha Power, A Problem from Hell: America and the Age of Genocide (New York: Basic Books, 2002).

${ }^{8}$ Rebecca Berg, “Foreign Policy Experts Discuss Ways to Avert Future Genocide," The New York Times, July 25, 2012, A8, accessed May 11, 2017, http://www.nytimes.com/2012/07/25/world/clinton-and-other-experts-discuss-ways-to-avertgenocide.html.

${ }_{9}^{9}$ Atul Gawande, The Checklist Manifesto: How to Get Things Right (New York: Metropolitan Books, 2009).

${ }^{10}$ Paul Brest and Linda Hamilton Krieger, Problem Solving, Decision Making, and Professional Judgment: A Guide for Lawyers and Policymakers (Oxford: Oxford University Press, 2010).

${ }^{11}$ Rex Brown, Rational Choice and Judgment: Decision Analysis for the Decider (Hoboken: John Wiley \& Sons, 2005).
} 
discipline" - derives from studies in decision analysis, ${ }^{12}$ psychology ${ }_{1}^{13}$ and behavioral economics. ${ }^{14}$ It maintains that peoples' unaided judgment is prone to numerous biases and errors, particularly when decision contexts are novel, choices are sequential and shared (i.e., requiring multiple decisions among multiple individuals), or when the task of balancing diverse objectives is critical.

\section{Prescriptive Decision Aids}

Prescriptive decision making is concerned with how people can improve their choice processes. As succinctly characterized in the book Smart Choices, ${ }^{15}$ a recommended decision-making sequence forms the acronym PrOACT: understand the Problem context, clarify Objectives and associated measures, define Alternatives, identify their likely Consequences and important uncertainties, and highlight key Trade-offs. When used in an iterative fashion, cycling back to re-examine assumptions due to shifts in the importance of different objectives or because new information is available, the approach is both rigorous and links with the logic of common sense.

To the extent that similar decisions are made over time, the use of a consistent decisionmaking framework encourages learning because it facilitates the comparison and review of choices, examining criteria and reasons that (in hindsight) will turn out to have a stronger or weaker rationale. The use of a simplifying structure to address intervention choices also has the benefit of forcing decision makers to confront a paradoxical truth: it is because the issues involved in framing such choices can appear overwhelmingly difficult that a simplifying structure is useful. Without an organizing structure, the breadth of concerns involved in thinking about interventions to prevent genocide can effectively serve to paralyze rational decision making. As a result, what often happens is that the difficult becomes (falsely) easy by relying on a single consideration (what is the dominant concern?), habit (what did we do last time?) or intuition (what is my gut feeling?). Unstructured discussions often serve to bias decisions in favor of short-term, emotionally satisfying goals (they attacked us so we'll attack them) or achieving objectives that are easy to defend, such as national security, without carefully weighing these against less prominent, more long-term, or more difficult-to-achieve objectives such as enhancing human rights or reducing the loss of civilian lives. ${ }^{16}$

In our experience, significant clarity can be gained through the simple act of developing a common language for the key decision elements and placing considerations into their proper place or order-an organizing or binning process referred to as "decision sketching." ${ }^{17}$ The structuring process begins by identifying a small set of objectives that effectively capture the concerns that matter most in the context of a defined problem. Alternative responses can then be compared in terms of their ability to achieve these identified values; the outcomes collectively determine the overall benefits and costs of any selected policy. Some of the consequences will matter more to some people than to others, which can help to shed light on individuals' underlying values as well as their interpretation of the available facts. The balancing of these different outcomes forms the basis for discussions of trade-offs: how much of a potential gain in one objective is needed to offset potential losses in another?

A decision-aiding approach uses several specific tools to help structure deliberations about tough intervention choices, with the goal of highlighting key considerations and-by making relationships among key decision elements more transparent-encouraging participants to pay

\footnotetext{
${ }^{12}$ John S. Hammond, Ralph L. Keeney, and Howard Raiffa, Smart Choices: A Practical Guide to Making Better Decisions (Cambridge, MA: Harvard Business School Press, 1999).

${ }^{13}$ Sarah Lichtenstein and Paul Slovic, The Construction of Preference (New York: Cambridge University Press, 2006); Daniel Kahneman, Thinking, Fast and Slow (New York: Farrar, Straus and Giroux, 2011).

${ }^{14}$ Paul R. Kleindorfer, Howard C. Kunreuther and Paul J. H. Schoemaker, Decision Sciences: An Integrative Perspective (Cambridge, UK: The Press Syndicate of The University of Cambridge, 1993).

${ }^{15}$ Hammond et al., Smart Choices.

${ }^{16}$ Paul Slovic and Daniel Västfjäll, "The More Who Die, the Less We Care: Psychic Numbing and Genocide," in Behavioral Public Policy, ed. Adam Oliver (Cambridge, UK: Cambridge University Press, 2013), 94-114.

${ }^{17}$ Robin Gregory, et al, Structured Decision Making: A Practical Guide to Environmental Management Choices (Chichester: Wiley-Blackwell, 2012).
} 
attention to areas of agreement and disagreement. Four tools drawn from the decision sciences are particularly helpful.

Objectives hierarchies provide a vehicle for identifying and ordering concerns relevant to a decision. ${ }^{18}$ For example, key values for intervention decisions to prevent mass atrocities and genocide will typically include effects on national security (including both domestic and international political or economic threats), loss of lives and injuries (both domestic and foreign), economic costs of intervention and aid, effects on the nation's reputation (related to meeting moral and legal obligations), and the anticipated impacts on regional stability. Each of these fundamental concerns often will include several sub-objectives: "protecting human lives," for example, includes deaths and injuries that might affect either civilians or members of the military. Delineating objectives (a) provides a clear basis and record for identifying what matters to the decision, (b) identifies an explicit and consistent framework for comparing the consequences of alternative actions or for generating new, creative alternatives, and (c) allows different participants to express the importance they place on each concern, which often provides the rationale for disagreements regarding choices.

Means-ends networks (also known as influence diagrams) are a common decision structuring or modeling tool that graphically represents the relationship between decisions, uncertainties and outcomes, using nodes and arrows. ${ }^{19}$ They emphasize the causal variables over which decision makers have some control and their sequential influence on the values and objectives at stake: an increase in funding for on-site medical personnel is a means that leads to better-staffed hospitals which, in turn, allows for lower response times and helps to achieve the fundamental (i.e., end) objective of saving more lives (see Figure 1). These diagrams can play an important role in defining evaluation criteria to better estimate the consequences of different courses of action and improve understanding of ways to achieve strategy objectives: meeting with leaders in Congress could be shown as a useful as a way to build support and, in turn, to maximize domestic political acceptance of proposed actions intended to protect the nation's security. Moreover, means-ends networks provide an easily accessible visual tool that facilitates communication among technical experts, decision makers, and stakeholders about their understanding of the decision context, what information is important, and why.

Performance measures establish one or more specific metrics (aka attributes) that account for changes in the achievement of objectives related to an action. Developing good measures for each interest is essential to the consistent evaluation of alternatives and also permits clear communication about what matters among the decision participants. To work well, performance measures should be understandable, complete (otherwise important concerns are omitted), concise (to facilitate the ready comparison of alternatives), direct and unambiguous (to ensure clear communication), and measurable (so that data can be found to estimate consequences among different intervention alternatives) ${ }^{20}$ Coming up with good measures for some objectives is relatively easy, for example using dollars to measure cost. Other important objectives, such as "national security" or "national reputation," are more ambiguous and can be difficult to define. In his 2016 review of the "Obama doctrine," journalist Jeffrey Goldberg notes that within the Pentagon or State Department, America's "national-security credibility" is seen as "an intangible yet potent force." 21 Because vague definitions-however strongly held-can lead to misunderstandings among the different players, ${ }^{22}$ deliberations will be improved to the extent that different intervention

\footnotetext{
${ }^{18}$ Ralph L. Keeney, Value-Focused Thinking: A Path to Creative Decisionmaking (Cambridge, MA: President and Fellows of Harvard College, 1992).

${ }^{19}$ Ronald A. Howard, “Decision Analysis, Practice and Promise,” Management Science 43, no. 6 (1998), 679-695.

${ }^{20}$ Ralph L. Keeney and Robin Gregory, "Selecting Attributes to Measure the Achievement of Objectives," Operations Research 53, no. 1 (2005), 1-11.

${ }^{21}$ Jeffrey Goldberg, “The Obama Doctrine,” The Atlantic, April 2016, 74.

${ }^{22}$ This same problem arises in the context of many objectives considered straightforward to measure, such as using numbers of fatalities for lives lost. The issue is that any measure frames the objective using a specific lens; numbers of fatalities, for example, counts all deaths as equal and fails to distinguish the age and gender of people or the circumstances of their deaths.
} 


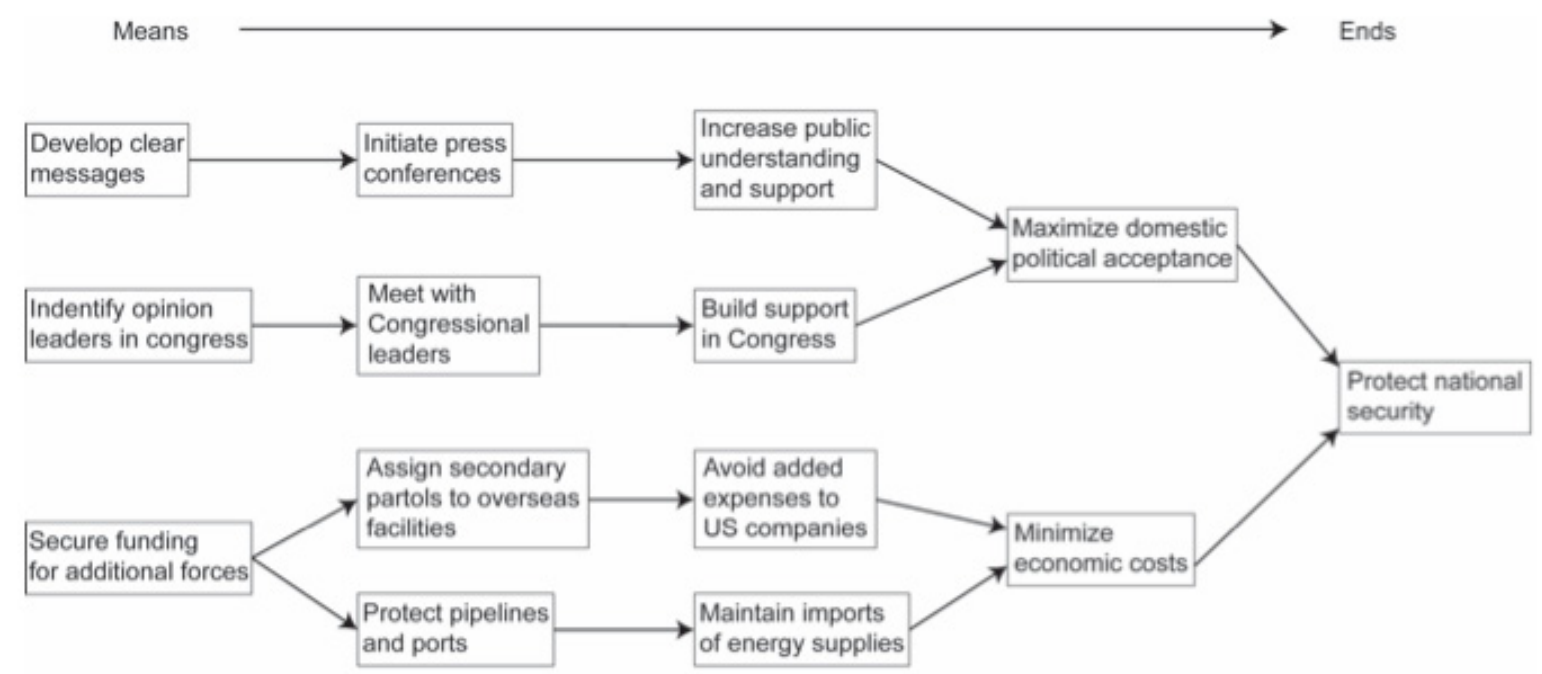

Figure 1. Illustrative (partial) means-ends network. The full-size version of this figure is available for download at http://doi.org/10.5038/1911-9933.11.3.1496.

alternatives can be compared on key dimensions and with all participants using the same working definitions.

Consequence tables are another key structuring tool, ${ }^{23}$ used to emphasize the link between the consequences of alternative actions and the concerns that matter the most. They provide a simple visual tool that conveys the anticipated changes across multiple accounts. As noted by Samantha Power: "You have to take into account the other collateral issues that you're dealing with on the international stage." ${ }^{24}$ Columns show the different intervention alternatives that are under consideration; rows show the different values that may be impacted. Each cell of the table thus shows what is likely to happen if that alternative is selected. Consequence tables can be kept simple or they can be constructed to incorporate additional considerations such as the existence of sequential decisions, information changes over time, thresholds signaling the need for possible shifts in actions, or important geographic differences among potentially affected regions. In complex decision contexts, consequence tables can also be used to highlight and characterize critical uncertainties and to express probabilities and confidence levels in the expected consequences of alternatives.

Expert elicitations provide a formal set of tools for incorporating the judgments of experts whenever data needed as part of an intervention decision is either lacking or of low quality, a situation that is common to many war-torn countries that are experiencing rapid and profound economic, environmental, or social changes. Although ad-hoc approaches are still widely employed, there exists a well-established consensus on best practices for selecting experts, setting up elicitation protocols, avoiding bias (such as being overconfident in one's knowledge or anchoring on recent events), aggregating across experts, and documenting findings so that their limits are clear and peer review is made easy. ${ }^{25} \mathrm{~A}$ common requirement is constructing a conceptual model that facilitates decomposition of a complex technical question into its component parts, which in turn allows for estimates of the uncertainty associated with the occurrence of these key elements. Experts are encouraged to assign plausible upper and lower bounds to the likelihood of an event as well as to identify the most likely value and the confidence held in their assessments. All of this information then becomes the basis for discussions among experts, which

${ }^{23}$ Robert T. Clemen and Terence Reilly, Making Hard Decisions with DecisionTools, 3rd ed. (Mason: South-Western, 2014).

${ }^{24}$ Evan Osnos, "In the Land of the Possible," The New Yorker, December 22 \& 29, 2014, 90-107.

${ }^{25}$ Mark A. Burgman, Trusting Judgements: How to Get the Best out of Experts (Cambridge, UK: Cambridge University Press, 2016). 
facilitates learning and leads to improved transparency in the comparisons that are made among alternatives.

\section{Fast vs. Slow Thinking}

A structured, decision-aiding process also can help to balance the role of two main judgmental mechanisms, involving the automatic and the more thoughtful responses that have been termed System 1 and System 2-fast and slow - thinking by Kahneman ${ }^{26}$ and others. System 1 is a fast, automatic system based on experience and involving intuition and feelings. System 2 brings in slower, more reasoned responses that involve cognition and analysis. Together these two ways of comprehending reality form the basis for how we identify and make difficult tradeoffs; different individuals and different groups-at the extreme, different countries-will rely on varying mixtures of System 1 and System 2 inputs when addressing intervention decisions.

A particular concern with respect to genocide prevention choices is that the fast, automatic thinking of System 1 can override the slower, more deliberate thinking of System 2 and lead to a reliance on emotional responses and judgmental shortcuts. Although these "judgmental heuristics" help decision makers to cope with the complex cognitive demands placed on them, they can also open the door to a variety of decision-making biases that lead individuals to anchor on past experience and oversimplified analogies or to give insufficient attention to their own perspective and values, thus resulting in the well-known phenomenon known as "groupthink." Results from behavioral research also show that people facing multi-sided choices, particularly in crisis situations, often tend to focus on only one or two prominent dimensions of a choice to the neglect of other considerations that they previously have said to be important (Slovic, 2015). Awareness of these judgmental biases - which research has shown to influence the choices and reasoning processes of experts as well as laypersons - can help significantly to improve the quality of decisions and aid in balancing the contributions of our System 1 and 2 inputs to choices.

\section{Understanding Psychological Influences}

Both policy makers and citizens ask themselves similar questions when considering the wide range of genocide prevention intervention strategies: What can we do to halt or reduce the killing of civilians? How do we even think about such large-scale losses of human lives? How do we decide when we are doing enough?

These questions bring into play - for individual citizens and for national policy makers - a mix of feelings and empathy that can run counter to the rational argument that the larger the loss of life, the more serious the problem and the stronger the case for intervention. ${ }^{27} \mathrm{~A}$ key insight from research into how people frame choices concerned with helping others - whether focused on charitable giving or taking actions to prevent harms or civilian deaths - is that people often exhibit a sharply diminishing sensitivity to what should be meaningful differences in the numbers of affected people. Although an argument can be made that large losses of life are disproportionately more serious, because they may threaten the social fabric or viability of a community or group, research clearly has shown that the importance of saving one life is large when it is the first, or only, life saved but diminishes as the total number of lives at risk increases. ${ }^{28}$ This effect, known as psychic numbing (or, in the context of charitable giving, as compassion fade), can be extreme. In some situations, for example, the value of protecting two lives is less than twice the value of protecting one life, and the value of saving 10,000 lives not significantly different from saving 100 lives. It appears that peoples' System 1 automatic, fast thinking systems can visualize and feel empathy for the plight of one person but this emotional connection quickly becomes tenuous as the number of people involved increases and statistics take the place of an identified person. ${ }^{29}$

\footnotetext{
${ }^{26}$ Kahneman, Thinking, Fast and Slow.

${ }^{27}$ Paul Bloom, Against Empathy: The Case for Rational Compassion (New York: Harper-Collins, 2016).

${ }^{28}$ Slovic and Västfjäll, The More Who Die.

${ }^{29}$ Deborah A. Small, George Lowenstein and Paul Slovic, "Sympathy and Callousness: The Impact of Deliberative Thought on Donations to Identifiable and Statistical Victims," Organizational Behavior and Human Decision Processes 102 , no. 2 (2007), 143-153.
} 
Psychic numbing is often enhanced by an accompanying (and often false) feeling of inefficacy, that nothing important can be done about the underlying issue. Although we can get our heads and hearts around helping one person at risk, helping hundreds or thousands of people at risk seems like it is beyond our capacity to make a difference This feeling of pseudo-inefficiency leads us to believe that nothing we do will be effective, leading to inaction and passivity; similar feelings may lie behind the lack of response on the part of many individuals to other large-scale global issues such as climate change. ${ }^{30}$ The problem is that although it is true that these are massive and urgent issues, in fact the actions taken by individuals - considered one by one, or when summed across many people-can make an important difference.

A third reason for lowered levels of concern in the face of mass atrocities is that intervention decisions involve multi-sided trade-offs. We care about the lives of civilians in other countries but we also worry about the cost of an intervention, whether it will be successful, and whether America's long-term security will be improved. In such circumstances other considerations, thought to be justified more easily than the uncertain ability to save foreign lives, often become more prominent and capture both peoples' attention and the bulk of public resources. Thus "homeland security" or "the national interest," despite being only vaguely defined, may be viewed by policy makers as more easily justified; to the extent these objectives conflict with other goals of intervention, then little may be done to address the ongoing loss of innocent civilian lives. ${ }^{31}$

These psychological mechanisms operate in the background as citizens and decision makers ponder what is an appropriate response to an emerging genocide or mass atrocity event. Different people will feel differently about proposed interventions to protect the lives of foreign civilians, and this is as it should be: our interest is not to push decision makers in one direction or another. Instead, our intent is to make sure that psychological tendencies such as psychic numbing, a false sense of inefficacy, or ignoring less prominent attributes, are not permitted to push us (or our elected representatives) into sub-optimal decisions, ones that they and we will regret and would want to change if only we had a better understanding of what is guiding our intervention choices.

\section{Communicating About Intervention Choices}

Decisions about whether to intervene to prevent or halt genocide and mass atrocities are rarely made by a single individual or a group at a single point in time. Instead, a small group or groups of experts (e.g., embassy staff within the country at issue along with colleagues working at the home office) typically assembles relevant data and frames various alternatives, then presents this information to other decision makers and elected officials. In addition to this internal dialogue there are often formal discussions with selected interest parties (e.g., allies, NGOs, and business leaders operating in the named country) and an informal dialogue with the general public (e.g., coordinated through the media).

These broader aspects of the intervention decision-making process, involving the justification and communication of possible intervention choices, are often neglected as part of analyses of intervention decision-making processes but hold important implications for their structure and outcomes. The prominence effect, noted earlier, can play a key role whenever political agendas enter into the picture. One result is that the expressed values of agency staff can be over-ridden by decision makers' perceived need to justify any eventual decision. As a result, humanitarian and other objectives that are thought to be more difficult to define or to defend, and that perhaps lack the emotional intensity of other concerns such as the maintenance of national security or positive relations with key allies, can be assigned less importance in the course of the decisionmaking process due to the perceived need to provide a defensible argument to elected officials or to citizens.

\footnotetext{
${ }^{30}$ Scott Slovic and Paul Slovic, Numbers and Nerves: Information, Emotion, and Meaning in a World of Data (Corvallis: Oregon State University Press, 2015).

${ }^{31}$ Paul Slovic, "When (In)action Speaks Louder than Words: Confronting the Collapse of Humanitarian Values in Foreign Policy Decisions," Illinois Law Review Slip Opinions, 2015, no. 1 (2015), 24-31.
} 


\section{Case Study: Structuring Intervention Decisions with Experts}

\section{Workshop Background and Participants}

To test these ideas and the role of decision-structuring aids in the context of decisions to prevent genocide and mass atrocities, a 1.5 day workshop involving experienced individuals was held in 2015 in Eugene, Oregon (with funding support from the U.S. National Science Foundation and the University of Oregon). Participants included Ambassadors, former officials of the U.S. Department of State, analysts, academics, and other knowledgeable experts with experience in genocide intervention decisions. Workshop objectives included discussing genocide intervention decision making processes and examining different decision aiding techniques that may improve deliberations related to intervention decisions. To ensure the relevance of workshop discussions and results, we enlisted the help of four invited participants-two Ambassadors, one Agency director, and one analyst-to review and comment on the agenda and background materials in advance of the workshop.

Our Day 1 introductory comments to the group emphasized that substantial insights often can be gained simply through organizing the various sources of decision complexity. To promote discussion, we presented the following initial listing of key contextual concerns, values, and alternatives:

- Decision context: geographic location, history, economic capabilities, leadership stability

- Values/objectives: national security, civilian lives and injuries (domestic, foreign), military lives and injuries (domestic, foreign), economic costs (intervention, aid), reputation of Nation (moral, legal, leadership), regional stability (social, political, economic)

- Intervention alternatives: diplomatic, economic, legal, military (covert or overt-air strikes, ground troops, etc.)

With this context as a common starting point, workshop participants explored a series of questions concerning the key elements of the decision context, the fundamental values that ultimately would determine whether the selected course of action was considered successful, and the various intervention alternatives that-singly or in combination-could be implemented. On Day 2 participants worked through a formal trade-off evaluation to explore each other's values and preferences and to identify the most sensitive factors influencing their choices. As several participants pointed out, this ordering of key decision elements could be reframed as a series of criteria or questions that might serve, in varying degrees, as a checklist to encourage more consistent thinking as part of any intervention decision.

\section{The Decision Problem}

All participants were provided with a short memo, reportedly from the U.S. Ambassador to the Assistant Secretary of State, which described the current humanitarian crisis in a fictional small Asian country (called "Adler") that threatens to soon expand to involve large numbers of civilian deaths and possibly genocide. Because this brief introduction necessarily left many questions unanswered-some of which typically would have been covered as part of agency memos and background discussions - participants were encouraged, as part of their small-group deliberations, to add (and document) contextual details as needed to proceed with a meaningful analysis of intervention choices.

The memo summarized the dramatic recent increases in violence as part of Adler's decadelong war between the ruling majority and rebels from an ethnic minority; participants were told that estimates placed the number of people killed over the past two years at 90,000, with civilian casualties accounting for over one-half the deaths. Information is scarce, however, with field reports infrequent since the recent killings of five foreign journalists (two American and three French). Rebel forces are demanding greater political and religious autonomy as well as a share of government funds received from petroleum exports, developed in conjunction with both U.S.based and Chinese companies. The government, which has been in power for nearly 20 years and continues to enjoy U.S. support, has demanded that rebels lay down their arms as a pre-condition to the renewal of negotiations, which broke off nearly three months ago. However, both sides continue 
to cite fundamental ethnic and religious differences. Some actions already have been undertaken: equipment has been brought in to jam TV and radio signals being used by rebel militants and the Ambassador has been working closely with neighboring countries to reduce the rebel's recruitment of fighters and supplies. In addition, a Financial Intelligence Unit has been formed to reduce rebel fund-raising through identification and freezing of foreign bank accounts. But the Ambassador's memo warns that new actions are urgently needed, with shipments of food and medicines largely prevented from reaching the areas most in need and large numbers of civilians-perhaps as many as 400,000 people-fleeing the country in search of safety and refugee status.

The Ambassador's memo was said to have prompted swift action from the Assistant Secretary of State, who called in six trusted advisers and led discussions focused on whether the US should quickly do more to prevent further civilian casualties and, if possible, to help stabilize the region. He prefaced his remarks by citing from the 2006 National Security Strategy that "Where perpetrators of mass killing defy all attempts to peaceful intervention, armed intervention may be required, preferably by the forces of several nations working together ..."32 The Ambassador remains in the country but arrangements are being made for her evacuation, along with the remaining five staff members.

Following the discussion of the problem context and the Ambassador's memo, a proposed objectives hierarchy was discussed based on the information contained within the briefing note (see Table 1). In contrast to the usual focus on alternatives, the development of an objectives hierarchy at the start of discussions was intended to provide a common framework for highlighting what is important and the key values that could be affected as a result of the proposed actions. This discussion further distinguished fundamental concerns (e.g., maintaining national security, protecting human lives) from means objectives or contributing factors (e.g., obtaining congressional support). In addition, the creation of the objectives hierarchy helped to build a common understanding of terms such as "national security," "national reputation," or "regional stability," which-as participants confirmed - often claim a front and center position in intervention debates despite their ambiguous definition..$^{33}$ The objectives hierarchy was also used to facilitate the identification of sub-objectives, more detailed components of these larger concerns that served to aid understanding and, in turn, could lead to evaluation criteria useful for assessing the different intervention alternatives.

Once a common set of objectives and sub-objectives had been outlined, participants turned their attention to thinking about how to express the different consequences of each intervention option in terms of these identified concerns. This part of the deliberations built on the concept of using explicit performance measures or attributes that would track the ability of each option to satisfy the different objectives highlighted for the scenario. In some cases familiar quantitative measures (such as dollars or lives) were used to express differences in the objectives across the alternatives. In other cases, when concerns were brought into the evaluation that lacked familiar measures or that required additional context, qualitative constructed scales were used (see Table 2). Keeping in mind the illustrative nature of this decision-structuring exercise, substantially less time was spent on the development of precise measures than would characterize a real-life intervention decision. Nevertheless, participants felt that - at least as a first approximation - the range of objectives, sub-objectives, and scales were sufficient to ensure a common understanding of key decision elements and to facilitate an initial comparison of the consequences of the different intervention options.

Performance measures are particularly useful in the type of multidimensional, highly nuanced decision environment that typically characterizes intervention choices. This is because they help add precision to what otherwise often are vague criteria, thereby lowering the quality of initial

\footnotetext{
${ }^{32}$ George W. Bush, The National Security Strategy of the United States of America (Washington, DC: The White House, 2006), 17.

${ }^{33}$ In his careful review of the APB, Finkel writes that "the Board's prescriptive deliberations" would be improved were it able to "develop a common understanding of what atrocity prevention means," in part because this would address the concern ". . that various Board members have very different notions about what prevention should and can accomplish." James P. Finkel, Atrocity Prevention at the Crossroads: Assessing the President's Atrocity Prevention Board After Two Years (Washington, DC: United States Holocaust Memorial Museum, 2014), 3, 20, 23.
} 
Table 1. Case study objectives hierarchy.

\begin{tabular}{|c|c|c|}
\hline Category (Fundamental Objective) & Sub-Objectives & $\begin{array}{l}\text { Potential Defining or Contributing } \\
\text { Factors (Illustrative) }\end{array}$ \\
\hline \multirow{5}{*}{$\begin{array}{l}\text { U.S. National Security } \\
\text { Within the context of assessing genocide } \\
\text { intervention decisions, national security } \\
\text { is broadly defined as potentially } \\
\text { weakening or destabilizing domestic } \\
\text { well-being. }\end{array}$} & Domestic Political & $\begin{array}{l}\text { Party support (internal) } \\
\text { Congressional support } \\
\text { Voter and public support }\end{array}$ \\
\hline & Foreign/International & $\begin{array}{l}\text { Consistency with and/or facilitating } \\
\text { U.S. foreign policy priorities } \\
\text { Support from key U.S. allies } \\
\text { Support from other countries or } \\
\text { agencies }\end{array}$ \\
\hline & Economic & $\begin{array}{l}\text { Costs to U.S. companies } \\
\text { National budget } \\
\text { Adverse energy security implications }\end{array}$ \\
\hline & Homeland Security & $\begin{array}{l}\text { Risk of terrorism (on U.S. soil) } \\
\text { Perception or feeling of insecurity }\end{array}$ \\
\hline & Exit Certainty & $\begin{array}{l}\text { Avoiding enlarged or protracted } \\
\text { conflict (certainty of exit strategy?) }\end{array}$ \\
\hline \multirow[t]{2}{*}{ Protecting Human Lives } & Civilian Lives (and Injuries) & $\begin{array}{l}\text { U.S. } \\
\text { Foreign }\end{array}$ \\
\hline & Military Lives (and Injuries) & $\begin{array}{l}\text { U.S. } \\
\text { Foreign }\end{array}$ \\
\hline \multirow[t]{2}{*}{ U.S. International Reputation } & Moral Imperative & $\begin{array}{l}\text { Requirement for action consistent } \\
\text { with what is the right thing to do }\end{array}$ \\
\hline & Legal Obligations & $\begin{array}{l}\text { Consistency with ratified agreements } \\
\text { / treaties (E.g. U.N. or Genocide } \\
\text { Convention) }\end{array}$ \\
\hline \multirow[t]{2}{*}{ Intervention Costs } & Costs to U.S. Government & $\begin{array}{l}\text { Administrative and management } \\
\text { costs } \\
\text { Military costs (equipment, salaries, } \\
\text { etc.) } \\
\text { Humanitarian Costs (food, housing, } \\
\text { medical—with vs. without } \\
\text { intervention) }\end{array}$ \\
\hline & Costs to Others & $\begin{array}{l}\text { Foreign governments } \\
\text { Foreign companies }\end{array}$ \\
\hline \multirow[t]{3}{*}{ Regional Stability } & Political & $\begin{array}{l}\text { Political upheaval } \\
\text { Balance of power in the region }\end{array}$ \\
\hline & Social & Social unrest \\
\hline & Economic & $\begin{array}{l}\text { Uncertainty \& losses to local/regional } \\
\text { economies }\end{array}$ \\
\hline
\end{tabular}

communication among decision participants and, at a later point in time, making it more difficult to evaluate the success of intervention initiatives. As noted by Power, ${ }^{34}$ a decision-aiding framework should not seek to homogenize these concerns and priorities but, rather, to clarify value differences and to help decision makers understand their implications. She identifies two primary aspirations of U.S. decision makers when facing mass atrocities: to "avoid engagement in conflicts that posed little threat to American interests" and to "contain the political costs and avoid the moral stigma

\footnotetext{
${ }^{34}$ Power, A Problem from Hell, 508.
} 
Table 2. Constructed scale used for estimating consequences of case study genocide intervention scenario.

\begin{tabular}{|c|c|}
\hline+3 & Significant Improvement: a significant net improvement is expected compared to current conditions \\
\hline+2 & Moderate Improvement: a moderate net improvement is expected compared to current conditions \\
\hline+1 & Small Improvement: a small but measurable improvement is expected compared to current conditions \\
\hline 0 & $\begin{array}{l}\text { No change: no changes are expected to occur relative to current conditions (i.e. neither a measurable } \\
\text { improvement nor a worsening in conditions) }\end{array}$ \\
\hline-1 & $\begin{array}{l}\text { Small Deterioration: conditions are expected to worsen slightly (but measurably) compared to current } \\
\text { conditions }\end{array}$ \\
\hline-2 & Moderate Deterioration: conditions are expected to worsen moderately compared to current conditions \\
\hline-3 & $\begin{array}{l}\text { Significant Deterioration: conditions are expected to worsen significantly compared to current } \\
\text { conditions }\end{array}$ \\
\hline
\end{tabular}

associated with allowing genocide." Being true to these two concerns requires an understanding of the other interests that also matter to decision makers, the types of threats that might be posed to specific American interests, and what kinds of political or moral costs might arise as the result of various levels of engagement in foreign conflicts.

Pre-workshop discussions with collaborating participants led to the generation of five intervention options-drawn from a much larger set of possible actions, but useful to help focus discussions - that would likely form the basis of intervention choices. These are briefly described below and also are shown as the columns in Figure 2.

- A first option is to continue the current "economic sanctions but no intervention" strategy, perhaps with the addition of new educational or communications initiatives.

- A second ("train and arm") strategy would involve the identification of critical gaps in Adler's military capability and bringing in needed new military equipment for use by Adler's army. Costs for the one-year operation are about $\$ 250$ million.

- A third option ("air strikes") would initiate bombing raids on rebel forces, using a U.S. aircraft carrier as a base of operations and working in conjunction with allied air forces. The targeted air strikes on rebel centers would cost nearly $\$ 100$ million/month and limit demands on an already overstretched U.S. military, but they could further reduce the amounts of food available in the markets and lead to criticism of foreign intervention.

- A fourth alternative ("safe zones"), to be organized in concert with regional and international allies, would bring in as many as 6,000 ground troops (half from the U.S.) to help create safe zones in areas of central Adler now experiencing the heaviest fighting. Initial cost estimates for the U.S. share of the military intervention range from $\$ 3-5$ billion, with concerns expressed by the White House about possible U.S. military casualties and adverse domestic implications as well as negative effects on the international reputation of the U.S.

- A fifth alternative ("full military intervention"), favored by some members of Congress, would seek to defeat rebel troops by bringing in as many as 60,000 U.S. ground soldiers and an equal number of troops from allies, with U.S. military personnel working alongside members of Adler's military and cleared for combat roles. Key arguments in favor include the moral and legal obligations of the U.S. to prevent foreign civilian deaths and to protect the interests of U.S. oil companies, U.S. costs would be as high as $\$ 5$ billion, support among other countries is mixed, and questions are being raised about the lack of a clear exit strategy. 


\begin{tabular}{|c|c|c|c|c|c|c|c|}
\hline Objective & Units & Dir & $\nabla^{5}$ & $p^{2}$ & $p^{2}$ & $p$ & $p$ \\
\hline \multicolumn{8}{|l|}{ National Secuity } \\
\hline US public support & \# & $\mathrm{H}$ & 0 & 1 & 0 & -1 & -2 \\
\hline Foreign ally support & \# & $\mathrm{H}$ & -1 & 1 & 0 & -1 & -2 \\
\hline Costs b US firms & \# & $\mathrm{H}$ & -3 & -2 & -1 & 0 & 0 \\
\hline Horneland security & \# & $\mathrm{H}$ & 0 & 0 & 0 & 0 & 0 \\
\hline Ext Certainty & \# & $\mathrm{H}$ & 1 & 0 & -1 & -3 & 2 \\
\hline \multicolumn{8}{|l|}{ Protecting Lives } \\
\hline Civilan lives saved & \# & H & 0 & 50,000 & 100,000 & 400,000 & 500,000 \\
\hline US military deafis & $\#$ & L & 2 & 10 & 25 & 100 & 250 \\
\hline \multicolumn{8}{|l|}{ US Reputation } \\
\hline Moral requirement & * & $\mathrm{H}$ & -2 & 1 & 1 & 2 & 3 \\
\hline InfI Legal Oblgatoms & w & $H$ & .2 & 0 & 0 & 2 & 3 \\
\hline \multicolumn{8}{|l|}{ Financial } \\
\hline Costs bo US (Yr 1) & US \$ (milons) & $\mathrm{L}$ & 50 & 250 & 2,000 & 5.000 & 20,000 \\
\hline Costs wo Chers $(\gamma r$ 1) & US S (milons) & $\mathrm{L}$ & 2.000 & 2.000 & 5,000 & 7,000 & 15,000 \\
\hline \multicolumn{8}{|l|}{ Regional Stability } \\
\hline Economic Stabäty & XOP & H & $-25 \%$ & $-20 \%$ & $-15 \%$ & $-15 \%$ & $-10 \%$ \\
\hline
\end{tabular}

Figure 2. Consequence table for case study genocide intervention scenario. The full-size version of this figure is available for download at http://doi.org/10.5038/1911-9933.11.3.1496.

These structured decision elements were then used to predict and compare the consequences of the different intervention alternatives. These effects were summarized through a consequence table (Figure 2) that shows the concerns in rows and the five leading intervention options in columns. This visual display was useful in that it facilitated discussions of the pros and cons of different actions and, in some cases, led to the refinement and alteration of the anticipated consequences as new information was shared among the participants. ${ }^{35}$ To more easily compare the performance between alternatives, the consequence table was color-coded to highlight significant differences in the performance measures relative to the selected reference alternative (the blue column in Figure 3); programming easily shows this comparison with reference to any of the alternatives. The use of colors facilitates the comparison of how well an alternative achieves each of the stated objectives: ${ }^{36}$ cells shown in green mean that another alternative is preferred for that objective, cells shown in red mean that alternative is inferior with respect to the objective, and cells with no shading are functionally identical to the highlighted reference alternative.

Workshop participants undertook two distinct prioritization techniques-direct ranking and swing weighting - to identify their preferences about the intervention alternatives. Both involve the elicitation of experts and include techniques intended to minimize the judgmental errors (discussed in Section 2.1) which can bias experts' opinions. Direct ranking is a more intuitive and experiential technique (often associated with System 1 thinking and very common within governments) where the best option is selected outright: given a set of alternatives, which one is preferred? Swing weighting is a more deliberative and analytical technique (i.e., more closely aligned to System 2 thinking) whereby a preferred option is inferred based on the relative importance (i.e., the weights) assigned to the different sub-objectives that characterize, to a greater or lesser degree, each of the specified options. Direct ranking of alternatives is therefore viewed as more holistic and ranking of sub-objectives (through swing weighting) as more decomposed.

An important point-often missed as part of policy assessments-is that the value weights reflect importance of the relative differences in each of the sub-objectives rather than the importance of the sub-objective as a category. In other words, it is not just how important a particular objective

\footnotetext{
${ }^{35}$ The illustrative nature of this case study meant that there was less information than usually would be available; as a result, more rows of the consequence table are, of necessity, filled in using constructed scales.

${ }^{36}$ Keeney and Gregory, Selecting Attributes to Measure.
} 


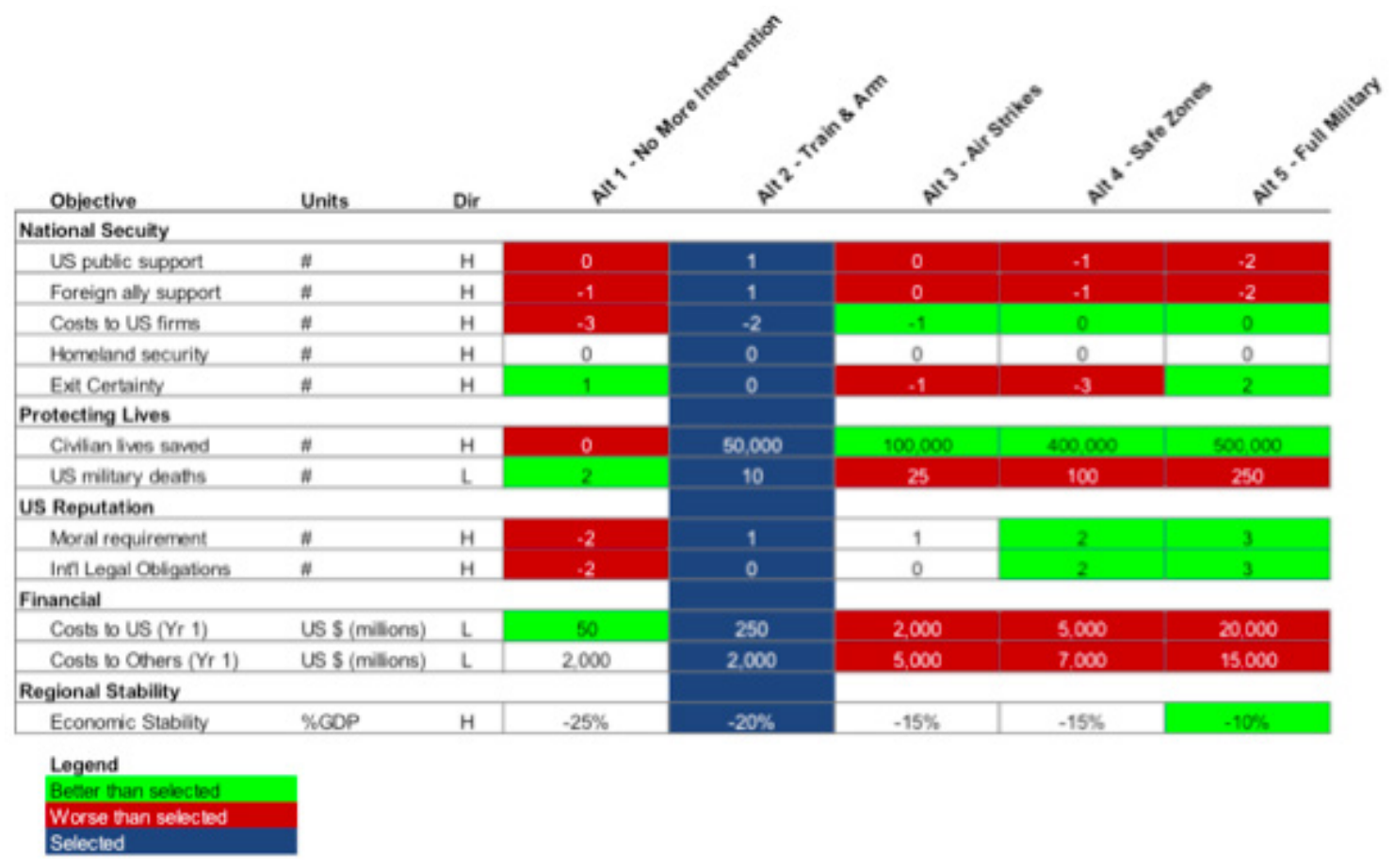

Figure 3. Color-coded consequence table (using Alt 2 as the reference alternative). The full-size version of this figure is available for download at http://doi.org/10.5038/1911-9933.11.3.1496.

or sub-objective may be (such as national security) but also how much it varies across the set of alternatives: if a sub-objective is fairly insensitive (i.e., the estimated performance measure values do not vary significantly) then it will be less important, and have a correspondingly lower weight, for selection of a preferred alternative.

Our goal was to highlight possible differences in preferred intervention scenarios depending on which technique was used (see Figure 4) and to stimulate dialogue among workshop participants. This goal is in line with general advice about how to deal with complex problems; in a paper titled "The Realities of Risk-Cost-Benefit Analysis," for example, Fischhoff ${ }^{37}$ suggests that the logic of analysts is to "Decompose complex systems into manageable components and then calculate how they might perform together." However, decomposition brings its own set of challenges $^{38}$ and, for this workshop, we emphasized that neither technique necessarily provides the right answer; both have strengths and weaknesses. The decision-aiding benefit is that the two approaches offer different perspectives about people's values and the associated trade-offs, which in turn often allows individuals to learn more about their own values and the reasoning underlying their choices.

The incorporation of decision-aiding tools also allowed participants to explore the degree to which they preferred one alternative over another and to observe how their preferences varied relative to everyone else (Figure 5). In addition, the use of a more decomposed approach permitted the invited experts to unbundle their thinking and to see which objectives were most instrumental in determining their preferred alternative. As shown in Figure 6, some alternatives were very successful at satisfying one objective and other alternatives were successful at satisfying other objectives. Discussions clearly revealed that participants found this information to be helpful; as several workshop members told us, the use of these visual tools permitted them to gain a better understanding of their own preferences and, in some cases, to realize that adjustments in their scoring of alternatives were requested to represent their own values accurately.

\footnotetext{
${ }^{37}$ Baruch Fischhoff, “The Realities of Risk-Cost-Benefit Analysis,” Science 350, no. 6260 (2015), 527.

${ }^{38}$ Gregory et al., Structured Decision Making.
} 


\section{Direct Weighting}

Participant 1

Participant 2

Participant 3

Participant 4

Participant 5

Participant 6

Participant 7

Participant 8

Participant 9

Participant 10

Participant 11

Participant 12

\begin{tabular}{|c|c|c|c|c|}
$\begin{array}{c}\text { Alt 1 - No More } \\
\text { Intervention }\end{array}$ & $\begin{array}{c}\text { At 2- Train \& } \\
\text { Arm }\end{array}$ & $\begin{array}{c}\text { At 3-Air } \\
\text { Strikes }\end{array}$ & $\begin{array}{c}\text { At 4-Safe } \\
\text { Zones }\end{array}$ & $\begin{array}{c}\text { Avt 5 - Full } \\
\text { Military }\end{array}$ \\
\hline $4 \%$ & $42 \%$ & $33 \%$ & $21 \%$ & $0 \%$ \\
\hline $43 \%$ & $0 \%$ & $0 \%$ & $57 \%$ & $0 \%$ \\
$31 \%$ & $4 \%$ & $18 \%$ & $44 \%$ & $2 \%$ \\
\hline $6 \%$ & $61 \%$ & $18 \%$ & $12 \%$ & $3 \%$ \\
\hline $38 \%$ & $15 \%$ & $23 \%$ & $25 \%$ & $0 \%$ \\
\hline $10 \%$ & $50 \%$ & $5 \%$ & $15 \%$ & $20 \%$ \\
\hline $31 \%$ & $39 \%$ & $12 \%$ & $12 \%$ & $6 \%$ \\
\hline $7 \%$ & $37 \%$ & $22 \%$ & $30 \%$ & $4 \%$ \\
\hline $53 \%$ & $26 \%$ & $5 \%$ & $16 \%$ & $0 \%$ \\
\hline $13 \%$ & $26 \%$ & $5 \%$ & $53 \%$ & $3 \%$ \\
\hline $34 \%$ & $43 \%$ & $21 \%$ & $2 \%$ & $0 \%$ \\
\hline 24 & $12 \%$ & $6 \%$ & $59 \%$ & $0 \%$ \\
\hline
\end{tabular}

\section{Swing Weighting}

\begin{tabular}{lccccc} 
& $\begin{array}{c}\text { More } \\
\text { Intervention }\end{array}$ & $\begin{array}{c}\text { Alt 2 - Train \& } \\
\text { Arm }\end{array}$ & $\begin{array}{c}\text { At 3 - Air } \\
\text { Strikes }\end{array}$ & $\begin{array}{c}\text { Alt 4 - Safe } \\
\text { Zones }\end{array}$ & $\begin{array}{c}\text { Alt 5 - Full } \\
\text { Military }\end{array}$ \\
\hline Participant 1 & $10 \%$ & $23 \%$ & $22 \%$ & $24 \%$ & $20 \%$ \\
Participant 2 & $12 \%$ & $23 \%$ & $22 \%$ & $26 \%$ & $17 \%$ \\
\hline Participant 3 & $12 \%$ & $21 \%$ & $21 \%$ & $24 \%$ & $23 \%$ \\
Participant 4 & $11 \%$ & $22 \%$ & $22 \%$ & $26 \%$ & $20 \%$ \\
Participant 5 & $9 \%$ & $20 \%$ & $20 \%$ & $23 \%$ & $28 \%$ \\
Participant 6 & $10 \%$ & $24 \%$ & $23 \%$ & $26 \%$ & $18 \%$ \\
Participant 7 & $12 \%$ & $23 \%$ & $22 \%$ & $24 \%$ & $18 \%$ \\
Participant 8 & $13 \%$ & $23 \%$ & $22 \%$ & $24 \%$ & $19 \%$ \\
Participant 9 & $13 \%$ & $24 \%$ & $23 \%$ & $24 \%$ & $17 \%$ \\
Participant 10 & $10 \%$ & $23 \%$ & $22 \%$ & $25 \%$ & $20 \%$ \\
Participant 11 & $11 \%$ & $23 \%$ & $22 \%$ & $24 \%$ & $20 \%$ \\
Participant 12 & $12 \%$ & $23 \%$ & $22 \%$ & $25 \%$ & $18 \%$ \\
\hline
\end{tabular}

Figure 4. Participant direct ranking and swing weighting preferences. The full-size version of this figure is available for download at http://doi.org/10.5038/1911-9933.11.3.1496.

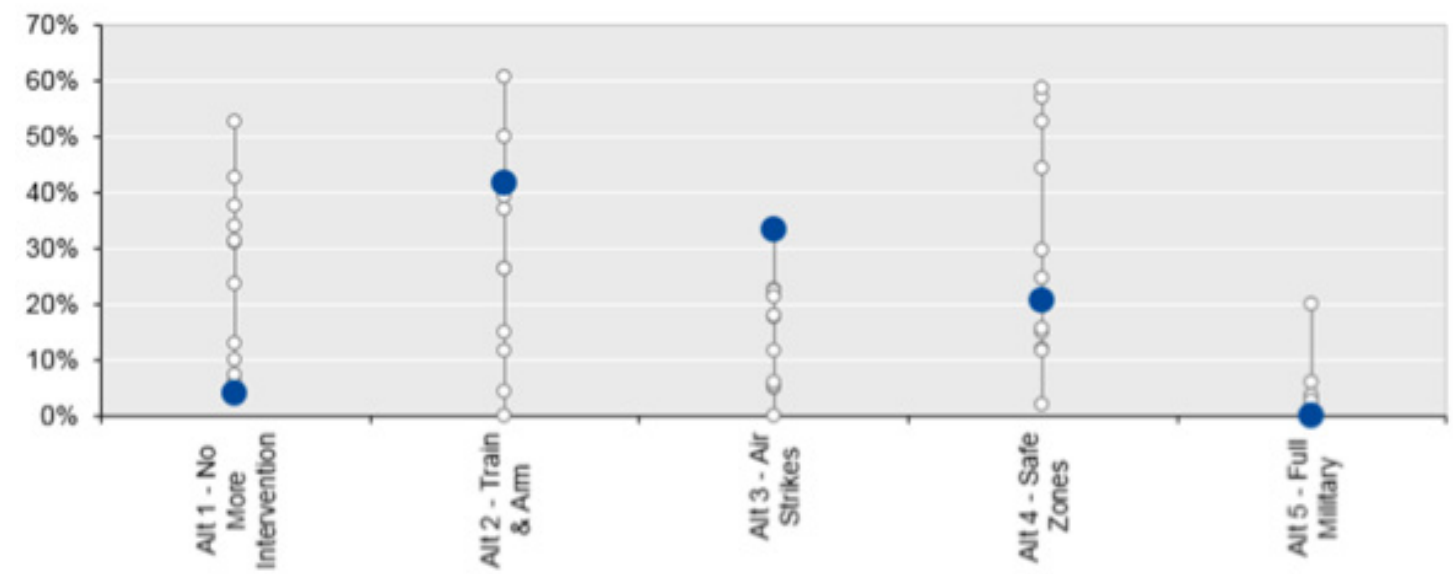

Figure 5. Direct ranking weights of Participant 1 (in blue) of their preferred intervention alternative relative to other participants. The full-size version of this figure is available for download at http://doi. org/10.5038/1911-9933.11.3.1496. 


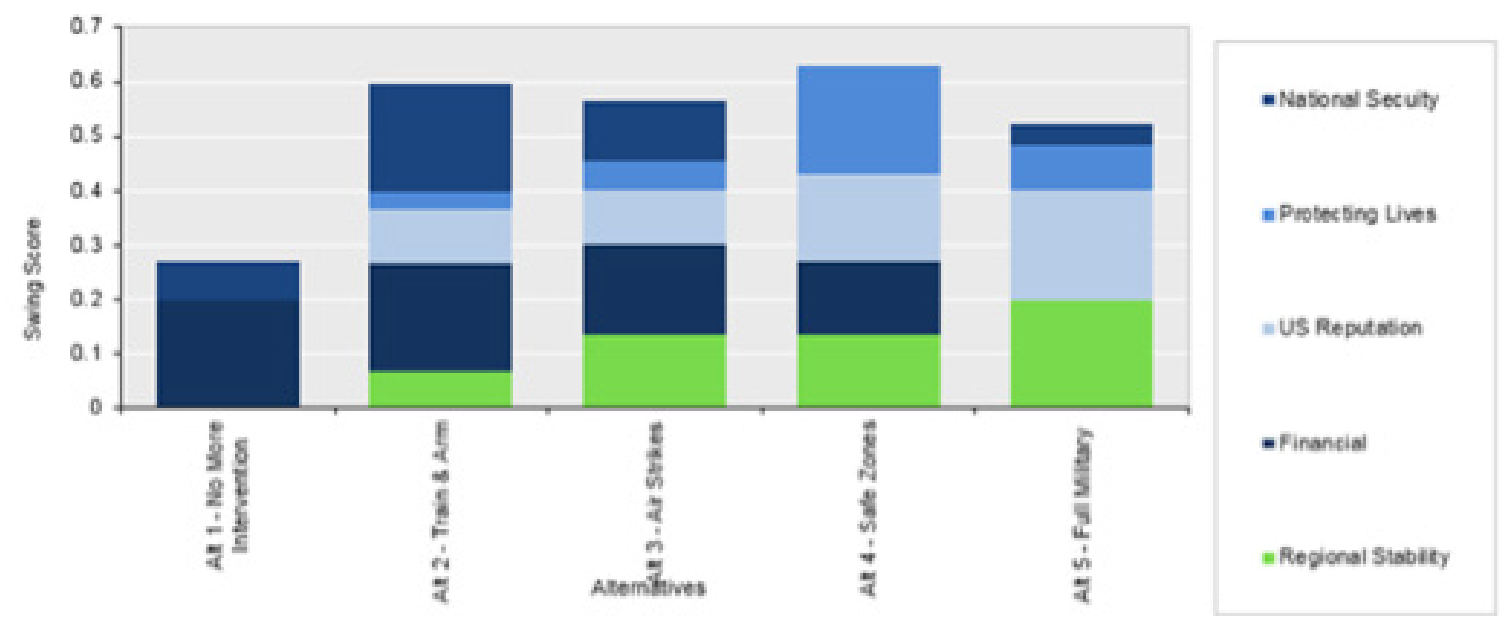

Figure 6. Relative importance of the objectives for Participant 1 in determining their preferred alternatives according to swing weighting. The full-size version of this figure is available for download at http://doi. org/10.5038/1911-9933.11.3.1496.

Discussions on Day 2 of the workshop then led to the use of two other methods as aids for further exploring participants' reasoning. Figure 7 digs deeper into the importance of each objective in shaping choices by showing the sensitivity of the weights placed by each participant on the different objectives and how changes, small or large, in these weights could lead to the selection of a different alternative. Finally, participants also were able to compare the consistency in their rankings and weightings according to the two techniques using consistency plots (Figure 8) that show their preferred alternatives: the closer preferences are aligned to the 45 degree line, the more consistent they are across the two techniques, which suggests the presence of greater stability. ${ }^{39}$

\section{Participant Feedback}

Participants' responses to the workshop were very positive, with an explicit values-based approach to making intervention decisions considered both new and promising. Some concerns were raised about the realism of the case-study scenario, which were anticipated; several of the participants had previous experience with scenario development lasting several weeks (e.g., through the National Defense University) and all participants, as part of their previous working experience, had been part of scenarios that took shape over years and with thousands of inputs. Nevertheless, a strong consensus emerged for adoption of a more structured framework to help in (a) untangling and organizing the fundamental values relevant to intervention deliberations, (b) highlighting potential decision biases that could lead to inferior choices, (c) clarifying information gaps and uncertainties critical to the decision context, and (d) exposing key trade-offs associated with different intervention choices.

As several participants pointed out, the framing of atrocities prevention as a core national interest and the initiation of high-level groups such as the Atrocities Prevention Board also underscore the importance of anticipating and preventing genocide as a fundamental interest of the United States. A keen interest was expressed by participants in identifying key elements that could help to characterize conflicts in the weeks or months prior to the escalation of violence and the beginnings of genocide or mass atrocities. If a more structured process could anticipate and target countries at risk of genocide and thus lead to effective, early-on intervention strategies, then the approach merits additional examination.

\footnotetext{
${ }^{39}$ We are well aware that this workshop focused on a hypothetical case-study and that not all groups would be so open to the sharing of information about the importance of objectives underlying members' expressed preferences; one implication is that increased anonymity might be required as part of the exploration of participants' reasoning in high-conflict situations.
} 

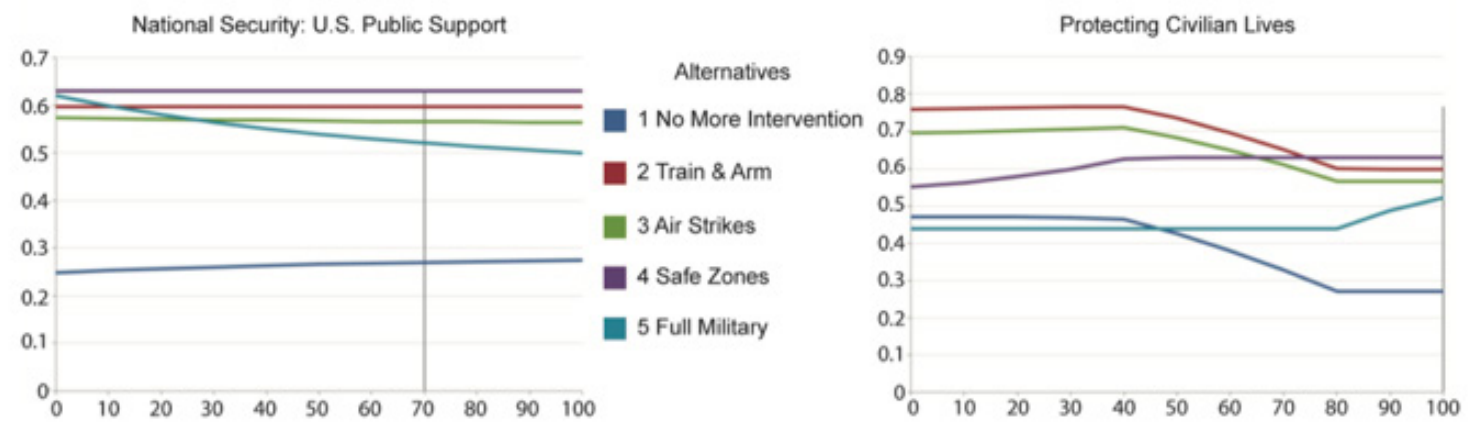

Figure 7. Swing weight sensitivity analysis for Participant 1 between consistency plot of Participant 1's preferred alternatives according to their direct ranking and swing weighted results. The full-size version of this figure is available for download at http://doi.org/10.5038/1911-9933.11.3.1496.

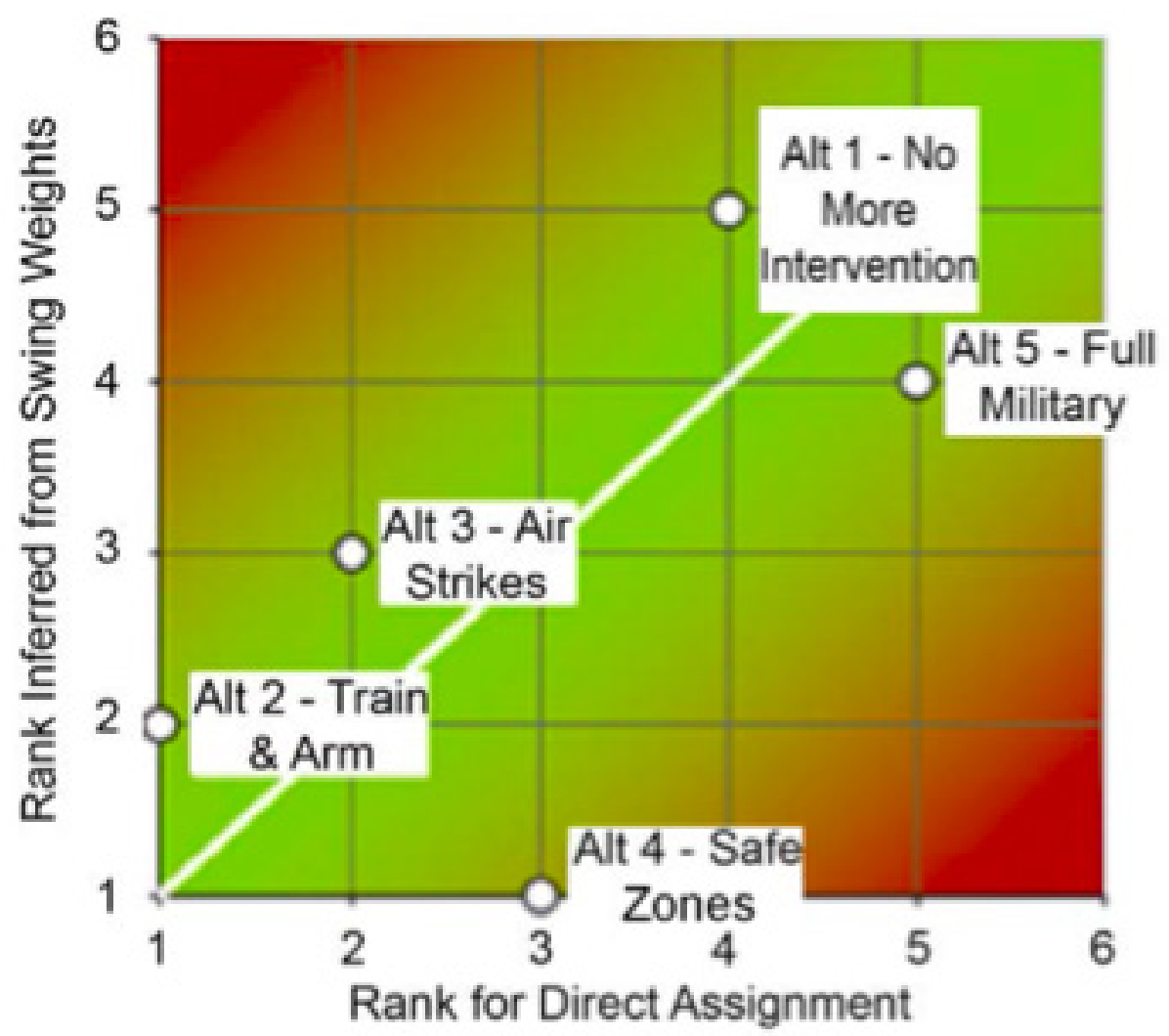

Figure 8. Consistency plot of Participant 1's preferred alternatives according to their direct ranking and swing weighting results. The full-size version of this figure is available for download at http://doi. org/10.5038/1911-9933.11.3.1496.

Questions also were raised by participants about whether use of a more structured process for identifying and scoring intervention alternatives might ask too much of participants in terms of requiring them to be honest and transparent about what matters, both to themselves and to the agency they represent. The workshop organizers are familiar with this concern and have observed it in other contexts; it is real, but no more so-no more difficult to address and overcome successfully -in the realm of intervention choices than for any other complex, multi-dimensional problem. Workshop participants also noted that many of the key intervention decisions are made by a small number of government staff who know each other well and are experienced in shared 
discussions, so that a basic level of ease and familiarity - at least in many situations - may already be established. This will aid in the creation of trust but it may also work against the introduction of any new approaches to analysis or deliberations.

\section{Conclusion and Recommendations}

The doctrine of responsibility to protect (R2P) ${ }^{40}$ articulated in 2005, permits the international community to intervene in the affairs of a sovereign state if it fails to protect its population from mass atrocity crimes. In this paper we argue in favor of adopting a more structured decision making process when considering possible intervention strategies that may help to prevent or reduce the threat of genocide and mass atrocities. We link this argument to several shortcomings associated with conventional deliberation processes, including paying attention only to more prominent objectives (such as national security or economic costs) in order to justify a given strategy and failing to respond appropriately to larger numbers of injuries and deaths because our automatic, feeling response does not easily scale up from one to many. The workshop results highlighted the insights that can be gained, in terms of the role of competing objectives and inferences, from the use of different elicitation techniques to help select a preferred alternative. Leaving these factors implicit takes away the opportunity for decision makers to learn more about their own preferences as well as others' views and can have the unintended result of discouraging interventions to save lives unless this humanitarian objective aligns closely with the other economic, national security, or reputational interests that underlie the intervention choice.

The use of different structuring techniques for displaying the results of the scenario-evaluation exercises successfully stimulated discussions and prompted a constructively critical review of participants positions: because choices were being made without access to perfect information and because time constraints were severe (as they also would be as part of most real-world intervention choices), it was important that individuals be given an opportunity to revisit their expressed values and opinions and to reconsider their choices in light of the new information that becomes available both through introspection and through subsequent discussions with colleagues. In addition, the more structured deliberative process led to several new hybrid intervention scenarios that may not otherwise have been identified.

We also note that uncertainty may play a complementary role in this de-emphasis of the humanitarian aspects of the choice. If estimates of cost or the anticipated impacts of national security risks are perceived as subject to less uncertainty than are foreign lives saved, then as a result they may be weighted relatively more heavily. Analysis can address this possible bias, at least to some extent, through the careful examination and communication of uncertainty and through an accurate summary of the uncertainty associated even with supposedly precise estimates (e.g., predictions of future prices or expenditures).

Yet despite the best of intentions and the adoption of appropriate techniques, decision makers may ignore the results of a more structured process, relying instead on System 1 intuitions and prior experience. In such cases, highlighting the key elements and consequences of an intervention choice will at minimum document the argument for selecting an intervention action-including what is left out of the picture as well as what is included - and all this information will be available and transparent if a subsequent review is conducted to determine why a selected strategy failed to meet expectations. In time, this information is likely to make it more difficult for decision makers to overturn the results of a thoughtful deliberative process.

Workshop results, including feedback from participants, provided clear support for our hypothesis that depicting genocide intervention decisions in terms of fundamental values, clearly articulated measures of performance, and the consequences of different alternatives can help to organize what is known about the predicted consequences of interventions while highlighting key information gaps. Because the primary goal of the workshop was to obtain feedback from these experienced participants regarding the potential advantages and disadvantage of a more structured framework for making intervention decisions, we did not formally seek to compare results of the

${ }^{40}$ United Nations, 2005 World Summit Outcome, paras. 138-140. 
holistic vs. decomposed approaches (e.g., through the use of control groups or over different contexts) other than to observe afterwards that the two approaches offered different insights to participants as aids for exploring which alternatives may best achieve their interests. Based on the initial positive feedback we received from participants, this is clearly a subject for future study; as several workshop members pointed out, the relevance of results would be improved to the extent that the decision-making situation is an actual, unfolding case study and involves individuals engaged in the decision-making process.

A more structured approach to intervention decisions also has the capability to examine carefully a vague doctrine, such as "promote the national interest" or "implement our responsibility to protect" and transform it into an organized framework that promotes both understanding and discussion. Of course, no decision-aiding framework can or should "make" the tough choices required of the US government with respect to interventions intended to reduce genocide and mass atrocities. What it can do is to improve the quality and extent of intervention deliberations, laying the groundwork for a more comprehensive and nuanced understanding of the threats posed to American values and interests using a common language for analysis that facilitates input and involvement from all key parties.

\section{Bibliography}

Albright, Madeleine K. and William S. Cohen. Preventing Genocide: A Blueprint for U.S. Policymakers. Washington, DC: United States Holocaust Memorial Museum, 2008.

Berg, Rebecca. "Foreign Policy Experts Discuss Ways to Avert Future Genocide." The New York Times, July 25, 2012, A8. Accessed May 11, 2017. http://www.nytimes.com/2012/07/25/ world/clinton-and-other-experts-discuss-ways-to-avert-genocide.html.

Bloom, Paul. Against Empathy: The Case for Rational Compassion. New York: Harper-Collins, 2016.

Brest, Paul and Linda Hamilton Krieger. Problem Solving, Decision Making, and Professional Judgment: A Guide for Lawyers and Policymakers. Oxford: Oxford University Press, 2010.

Brown, Rex. Rational Choice and Judgment: Decision Analysis for the Decider. Hoboken: John Wiley \& Sons, 2005. https://doi.org/10.1002/0471716898

Burgman, Mark A. Trusting Judgements: How to Get the Best out of Experts. Cambridge, UK: Cambridge University Press, 2016. https://doi.org/10.1017/CBO9781316282472

Bush, George W. The National Security Strategy of the United States of America. Washington, DC: The White House, 2006.

Clemen, Robert T. and Terence Reilly. Making Hard Decisions with DecisionTools, 3rd ed. Mason: South-Western, 2014.

Finkel, James P. Atrocity Prevention at the Crossroads: Assessing the President's Atrocity Prevention Board After Two Years. Washington, DC: United States Holocaust Memorial Museum, 2014.

Fischhoff, Baruch. "The Realities of Risk-Cost-Benefit Analysis." Science 350, no. 6260 (2015): 527. https://doi.org/10.1126/science.aaa6516

Gawande, Atul. The Checklist Manifesto: How to Get Things Right. New York: Metropolitan Books, 2009.

Goldberg, Jeffrey. “The Obama Doctrine.” The Atlantic, April 2016, 74.

Gregory, Robin, Lee Failing, Michael Harstone, Graham Long, Tim McDaniels, and Dan Ohlson. Structured Decision Making: A Practical Guide to Environmental Management Choices. Chichester: Wiley-Blackwell, 2012. https://doi.org/10.1002/9781444398557

Hammond, John S., Ralph L. Keeney, and Howard Raiffa. Smart Choices: A Practical Guide to Making Better Decisions. Cambridge, MA: Harvard Business School Press, 1999.

Howard, Ronald A. "Decision Analysis, Practice and Promise." Management Science 43, no. 6 (1998): 679-695.

Kahneman, Daniel. Thinking, Fast and Slow. New York: Farrar, Straus and Giroux, 2011.

Keeney, Ralph L. Value-Focused Thinking: A Path to Creative Decisionmaking. Cambridge, MA: President and Fellows of Harvard College, 1992.

Keeney, Ralph L. and Robin Gregory. "Selecting Attributes to Measure the Achievement of Objectives." Operations Research 53, no. 1 (2005): 1-11. https://doi.org/10.1287/opre.1040.0158 
Kleindorfer, Paul R., Howard C. Kunreuther and Paul J. H. Schoemaker. Decision Sciences: An Integrative Perspective. Cambridge, UK: The Press Syndicate of The University of Cambridge, 1993. https://doi.org/10.1017/CBO9781139173537

Lichtenstein, Sarah and Paul Slovic. The Construction of Preference. New York: Cambridge University Press, 2006. https://doi.org/10.1017/CBO9780511618031

Obama, Barack. Executive Order 13729 of May 16, 2016, A Comprehensive Approach to Atrocity Prevention and Response. Washington, DC: The White House, 2016.

. Presidential Directive Study 10, August 4, 2011. Washington, DC: Office of the Federal Register, 2011.

Osnos, Evan. "In the Land of the Possible." The New Yorker, December 22 \& 29, 2014, 90-107.

Power, Samantha. A Problem from Hell: America and the Age of Genocide. New York: Basic Books, 2002.

Remnick, David. "Going the Distance." The New Yorker, January 27, 2014. Accessed May 11, 2017. http://www.newyorker.com/magazine/2014/01/27/going-the-distance-david-remnick.

Slovic, Paul. "When (In)action Speaks Louder than Words: Confronting the Collapse of Humanitarian Values in Foreign Policy Decisions." Illinois Law Review Slip Opinions 2015, no. 1 (2015): 24-31.

Slovic, Paul and Daniel Västfjäll. "The More Who Die, the Less We Care: Psychic Numbing and Genocide." In Behavioral Public Policy, edited by Adam Oliver, 94-114. Cambridge, UK: Cambridge University Press, 2013. https://doi.org/10.1017/CBO9781107337190.005

Slovic, Scott and Paul Slovic. Numbers and Nerves: Information, Emotion, and Meaning in a World of Data. Corvallis: Oregon State University Press, 2015.

Small, Deborah A., George Lowenstein, and Paul Slovic. "Sympathy and Callousness: The Impact of Deliberative Thought on Donations to Identifiable and Statistical Victims." Organizational Behavior and Human Decision Processes 102, no. 2 (2007): 143-153. https://doi.org/10.1016/j. obhdp.2006.01.005

United Nations. General Assembly Resolution 60/1, 2005 World Summit Outcome. October 24, 2005. UN Doc. A/RES/60/1. 